Vietnam Journal of Mechanics, VAST, Vol. 27, No. 2 (2005), pp. 107-117

\title{
INFLUENCE OF EDGE CRACK ON FREQUENCIES OF THIN PLATE IN BENDING
}

\author{
Nguyen Thi Hien Luong and Vuong Quang Giang \\ Ho Chi Minh City University of Technology
}

\begin{abstract}
This paper investigates the influence of crack location and crack length on changes in natural frequencies of bending thin plate. To perform this analysis, a computing program called CRACK-PLATE, using the finite element method based on the RessnerMindlin' theory of plate is developed. In order to achieve a high accuracy, an isoparametric element of Barsoum is combined with an 8-node quadrilateral isoparametric element. The numerical results show that the natural frequencies are very sensitive to the crack presence in the bending thin plate. This study is a basis for crack identification based on natural frequencies of plates.
\end{abstract}

Key words. Bending cracked plate, frequency, finite element method, Ressner-Mindlin' theory of plate, element of Barsoum.

\section{INTRODUCTION}

Crack has great influence on load carrying capacity and lifetime of structures. The problem of exact determining the crack position and depth is very important, from there; one can predict the real capacity of structures and propose a timely solution to prevent damages.

In recent years, several authors have carried out natural frequency analysis of cracked beams [1-2] to detect the presence of a crack in beams, and determine its location and size, based on experimental dynamic analysis results... Meanwhile, crack detection in plates has been little mentioned. Cawley and Adams [3] introduced an effective method of nondestructively assessing the integrity of structures using measurements of the structural natural frequencies obtained from tests on an aluminum plate. Recently, Wu and Law [4] proposed a damage localization method for two-dimensional plate structures, based on changes in uniform load surface (ULS) curvature. However, these studies are mainly experimental. Thus, a study for influence of crack on frequency of plate is necessary and has real meaning. It provides a basis to perform the inverse problem for crack detection in plate using changes in frequencies.

This paper aims to study the influence of crack location and crack length on changes in frequencies of cantilever thin plate, by the computing program CRACK-PLATE written by Matlab 6.0 language, using the finite element method with an 8-node quadrilateral isoparametric element based on the Ressner-Mindlin' theory of plate. An isoparametric element of Barsoum, in which, the mid-side nodes are moved to quarter-point position, is combined to achieve the singularity near crack tip in linear elastic fracture mechanics. To verify the reliability of the CRACK-PLATE program, the numerical results are compared with ANSYS program. 


\section{GENERAL FORMULATION}

\subsection{Free vibration problem}

The equation of motion of a undamped free vibration structure are determined in the form $[5]$ :

$$
[M]\{\ddot{q}\}+[K]\{q\}=\{0\},
$$

where $[M]$ is the mass matrix, $[K]$ is the stiffness matrix, $\{q\}$ is the displacement vector and $\{\ddot{q}\}$ is the acceleration vector.

It will be assumed that the free vibration of structure is harmonic with natural circular frequency $\omega$ and amplitude $\{\bar{q}\}$ so equation (2.1) can be rewritten:

$$
\left([K]-\omega^{2}[M]\right) \cdot\{\bar{q}\}=\{0\},
$$

where $\omega=2 \pi f, f$ is natural vibration frequency. Hence, a nontrivial solution is possible only when

$$
\operatorname{det}\left([K]-\omega^{2}[M]\right)=0
$$

Expanding the determinant of equation (2.3) will give an algebraic equation of the $\mathrm{n}^{\text {th }}$ degree in the frequency parametric $\omega^{2}$ for a structure having $n$ degree of freedom. The $n$ roots of this equation represent the frequencies of the $n$ modes of vibration that are possible in the structure.

\subsection{Basic fracture mechanics}

Fracture mechanics admits the existence of an initial fissure in the structure under consideration that defines a local and irreversible separation of a continuous milieu at two borders, calls crack surfaces. The external solicitation tends to extend the fissures to different modes. There are three independent kinematical movements of the upper and lower crack surfaces with respect to each other and these are categorized as [6]:

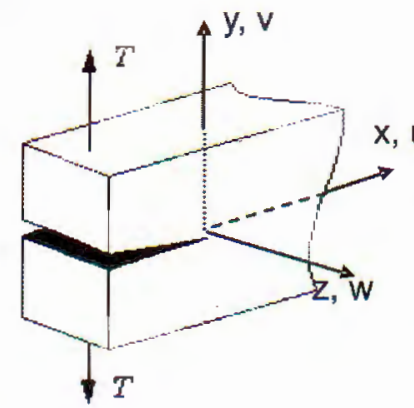

MODEI

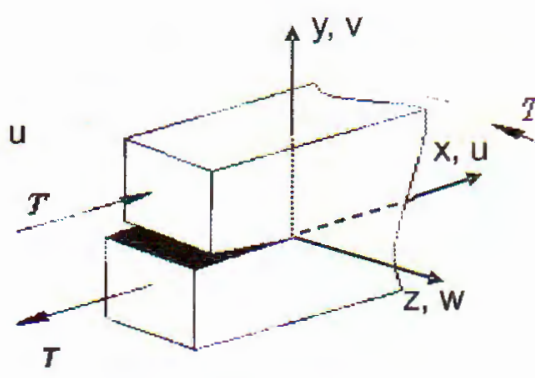

MODEI

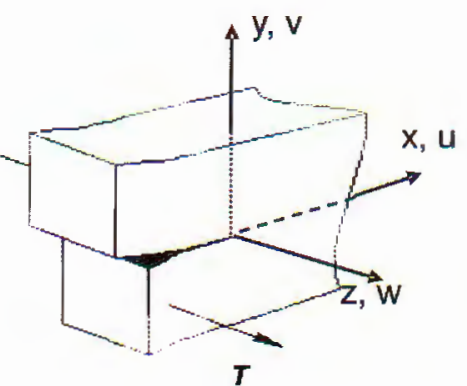

MODEIII

Fig. 1. The three modes of crack opening deformation

Opening mode (mode I): in which the two crack surfaces are pulled apart in their direction, but where the deformations are symmetric about the $x-z$ and $x-y$ planes. 
Sliding mode (mode II): in which the two crack surfaces slide over each other in the $\mathrm{x}$ direction, where the deformations are symmetric about the $x-y$ plane and skew symmetric about $x-z$ plane.

Tearing mode (mode III): in which the two crack surfaces slide over each other in the $z$-direction, where the deformations are skew symmetric about the $x-y$ and $x-z$ planes.

The appropriate superposition of these three modes describes the general case of cracking.

\subsection{Quadratic isoparametric element}

The shape functions for 8-node quadrilateral isoparametric element are given below [7]:

$$
\begin{aligned}
N_{i}(\xi, \eta)= & \frac{\xi_{i}^{2} \eta_{i}^{2}}{4}\left[\left(1+\xi \xi_{i}\right)\left(1+\eta \eta_{i}\right)-\left(1-\xi^{2}\right)\left(1+\eta \eta_{i}\right)-\left(1-\eta^{2}\right)\left(1+\xi \xi_{i}\right)\right] \\
& +\frac{\xi_{i}^{2}}{2}\left(1-\eta^{2}\right)\left(1+\xi \xi_{i}\right)\left(1-\eta_{i}^{2}\right)+\frac{\eta_{i}^{2}}{2}\left(1-\xi^{2}\right)\left(1+\eta \eta_{i}\right)\left(1-\xi_{i}^{2}\right)
\end{aligned}
$$

where $\xi_{i}, \eta_{i}= \pm 1$ at corner nodes and zero at mid-side nodes.

\section{Stiffness matrix of element}

The Reissner-Mindlin' theory of plate includes the effect of transverse shear deformation. Hence, the internal energy expression for the shear deformable plate should include the transverse shear energy as well as the bending energy and expressed as [7]:

$$
U=\frac{1}{2} \int_{V}\left\{\varepsilon_{b}\right\}^{T}\left[D_{b}\right]\left\{\varepsilon_{b}\right\} d V+\frac{\kappa}{2} \int_{V}\left\{\varepsilon_{s}\right\}^{T}\left[D_{s}\right]\left\{\varepsilon_{s}\right\} d V,
$$

where $\left\{\varepsilon_{b}\right\},\left\{\varepsilon_{s}\right\}$ are the bending and shear strains; $\kappa$ is the shear energy correction factor and equal to $\frac{5}{6} ;\left[D_{b}\right],\left[D_{s}\right]$ are the bending and shear elasticity coefficient matrices, which are defined as follows:

$$
\begin{gathered}
{\left[D_{b}\right]=\frac{E}{1-\nu^{2}}\left[\begin{array}{lll}
1 & \nu & 0 \\
\nu & 1 & 0 \\
0 & 0 & \frac{1-\nu}{2}
\end{array}\right] .} \\
{\left[D_{s}\right]=\frac{E}{2(1+\nu)}\left[\begin{array}{ll}
1 & 0 \\
0 & 1
\end{array}\right],}
\end{gathered}
$$

in which $E$ is the module of Young, $\nu$ is the Poisson's coefficient.

The element stiffness matrix for plate bending is expressed as:

$$
\left[K_{e}\right]=\frac{h^{3}}{12} \int_{-1}^{1} \int_{-1}^{1}\left[B_{b}\right]^{T}\left[D_{b}\right]\left[B_{b}\right]|J| d \xi d \eta+\kappa h \int_{-1}^{1} \int_{-1}^{1}\left[B_{s}\right]^{T}\left[D_{s}\right]\left[B_{s}\right]|J| d \xi d \eta
$$

where $h$ is the plate thickness. The matrices $B_{b}, B_{s}$ are defined as

$$
\left[B_{b}\right]=\left[\begin{array}{lll}
\frac{\partial N_{i}}{\partial x} & 0 & 0 \\
0 & \frac{\partial N_{i}}{\partial y} & 0 \\
\frac{\partial N_{i}}{\partial y} & \frac{\partial N_{i}}{\partial x} & 0
\end{array}\right], \quad\left[B_{s}\right]=\left[\begin{array}{lll}
-N_{i} & 0 & \frac{\partial N_{i}}{\partial x} \\
0 & -N_{i} & \frac{\partial N_{i}}{\partial y}
\end{array}\right]
$$


and

$$
[J]=\left[\begin{array}{cc}
\frac{\partial x}{\partial \xi} & \frac{\partial y}{\partial \xi} \\
\frac{\partial x}{\partial \eta} & \frac{\partial y}{\partial \eta}
\end{array}\right]=\left[\begin{array}{cccccc}
\cdot & \cdot & \frac{\partial N_{i}}{\partial \xi} & \cdot & . & \cdot \\
& \cdot & \cdot & \frac{\partial N_{i}}{\partial \eta} & & \\
\cdot & \cdot & .
\end{array}\right]\left[\begin{array}{ll}
: & : \\
x_{i} & y_{i} \\
: & :
\end{array}\right] .
$$

One thing to be noted in equation (2.8) that the shear energy becomes dominant compared to the bending energy as the plate thickness becomes very small compared to its side length. This is called a shear locking. To resolve this problem, the selective or reduced integration technique was proposed. For 8-node isoparametric element is used, the $3 \times 3$ Gauss-Legendre quadrature is used for the bending term and the $2 \times 2$ point integrations is used for the shear term.

\section{Consistent mass matrix of element}

In the normalized square space $(\xi, \eta),(-1 \leq \xi \leq 1,-1 \leq \eta \leq 1)$, the consistent mass matrix of element can be obtained [9]:

in which

$$
\left[M_{e}\right]=\rho h \int_{-1}^{1} \int_{-1}^{1}\left[N_{1}\right]^{T}\left[N_{1}\right]|J| d \xi d \eta+\frac{\rho h^{3}}{12} \int_{-1}^{1} \int_{-1}^{1}\left[N_{2}\right]^{T}\left[N_{2}\right][J] d \xi d \eta
$$

$$
\left[N_{1}\right]=\left[\begin{array}{lll}
0 & 0 & 0 \\
0 & 0 & 0 \\
0 & 0 & N_{i}
\end{array}\right] .\left[N_{2}\right]=\left[\begin{array}{lll}
-N_{i} & 0 & 0 \\
0 & -N_{i} & 0 \\
0 & 0 & 0
\end{array}\right]
$$

where $N_{i}$ is the shape functions and are given by equation (2.4). Equation (2.11) is computed with $3 \times 3$ point integrations Gauss-Legendre.

\subsection{Isoparametric element of Barsoum}
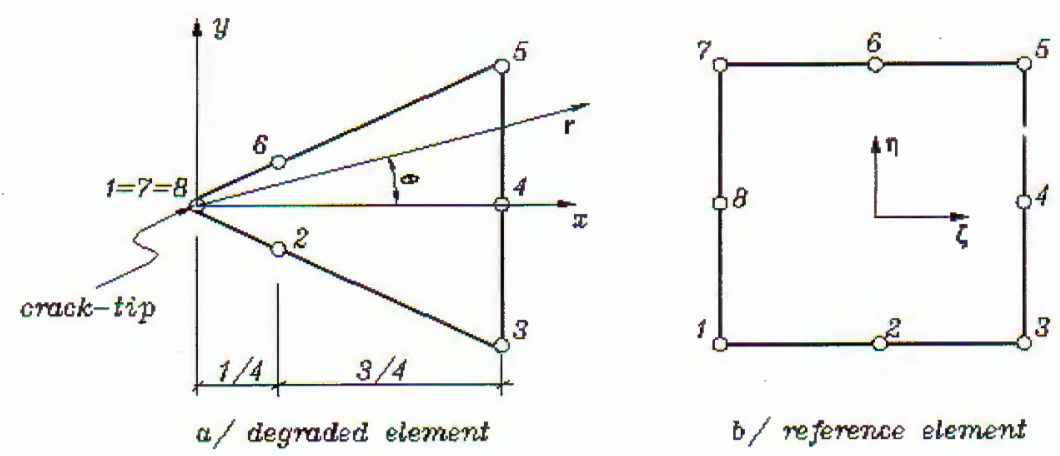

Fig. 2. Triangular element of Barsoum

Utilizing triangular element of Barsoum [8], we obtain the singularity $1 / \sqrt{r}$ of strain at the crack tip of that element by degrading an edge of the quadrilateral element and moving the mid-side nodes to the quarter point adjacent to the crack-tip (Fig.2). 
For this element, Barsoum has shown that:

$$
\begin{aligned}
& \frac{\partial u}{\partial x}=\frac{A_{0}}{\sqrt{r}}+A_{1}, \\
& \frac{\partial u}{\partial y}=\frac{B_{0}}{\sqrt{r}}+B_{1}, \\
& \frac{\partial v}{\partial x}=\frac{C_{0}}{\sqrt{r}}+C_{1}, \\
& \frac{\partial v}{\partial y}=\frac{D_{0}}{\sqrt{r}}+D_{1},
\end{aligned}
$$

where $A_{0}, A_{1}, B_{0}, B_{1}, C_{0}, D_{0}, D_{1}$ are constants. Thus, the use of the Barsou's s element can describe the singularity of strain and stress fields around crack-tip in the plate.

\section{NUMERICAL RESULTS AND DISCUSSION}

\subsection{Investigative procedure}

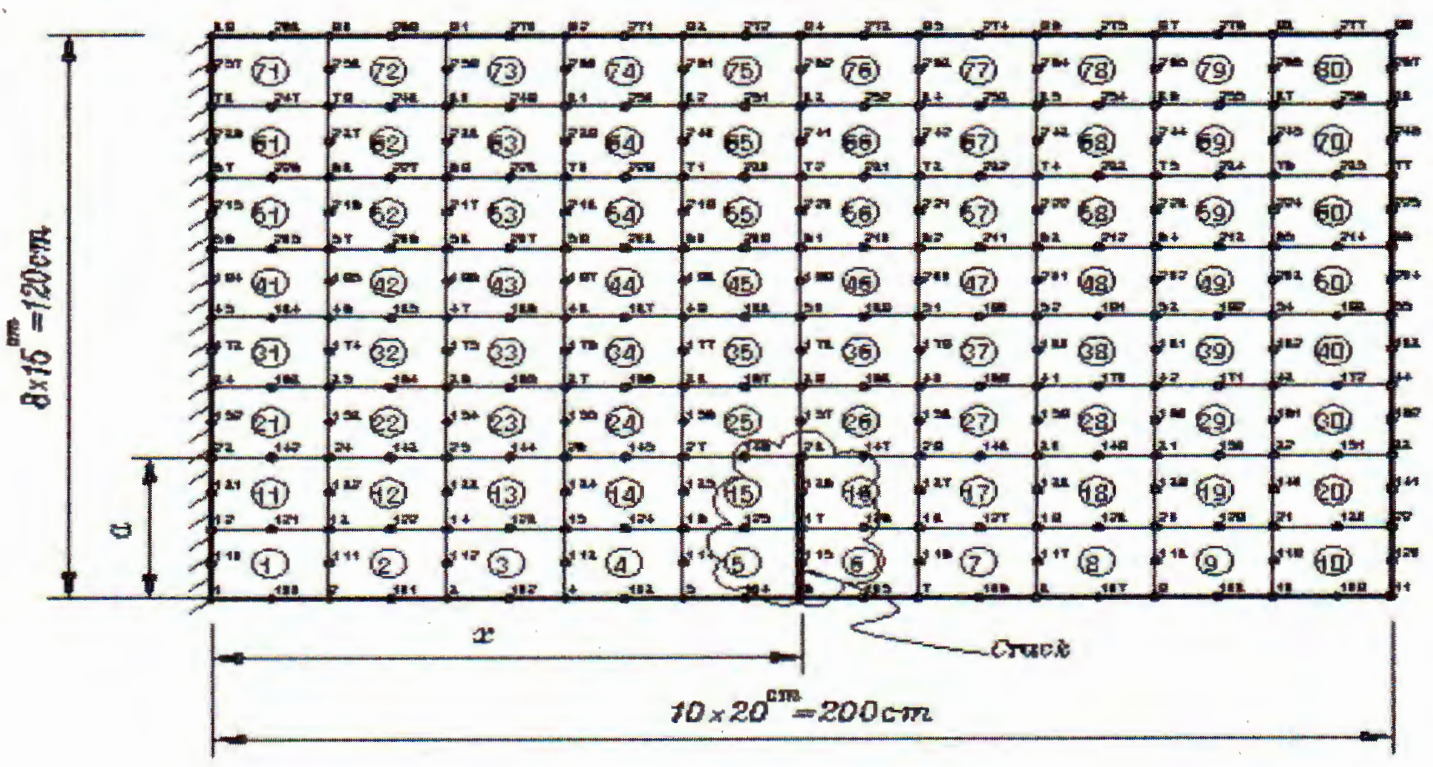

Fig. 3. Bending plate with an edge crack

Problem: Investigate the influence of crack location and crack length on changes in frequencies of bending thin plate with an edge crack (Fig. 3). The computing program CRACKPLATE, developed by Matlab 6.0 language, performs this problem.

Modeling of the problem: cantilever plate is meshed into 80 elements with an edge crack. Three d.o.f., which are translational along the $Z$-axis $(w)$ and rotational along the $X$-and $Y$-axis $\left(\theta_{x}, \theta_{y}\right)$, are used at each node. It is assumed that the crack location and the lines of mesh are coincident. The mesh around crack tip must have the shape as in the Fig. 4. Data input: - The module of Young: $E=2.65 \times 10^{8} \mathrm{~N} / \mathrm{m}^{2}$ 
- The Poisson's coefficient: $\nu=0.2$

- Density: $\rho=2500 \mathrm{~kg} / \mathrm{m}^{3}$

- Length of plate: $L=2 \mathrm{~m}$

- Width of plate: $W=1.2 \mathrm{~m}$

- Thickness of plate: $h=0.1 \mathrm{~m}$

The first four natural vibration frequencies of the uncracked plate are calculated. In this problem, the crack location ratio $(x / L)$ (the ratio of the location of a crack to the length of plate) varied from 0.1 to 0.9 with an increment of 0.1 , starting from a location near to the fixed end to a location near to the free end. Simultaneously, the crack length ratio $(a / W)$ (the ratio of the length of a crack to the width of plate) also varied from 0.125 to 0.5 with

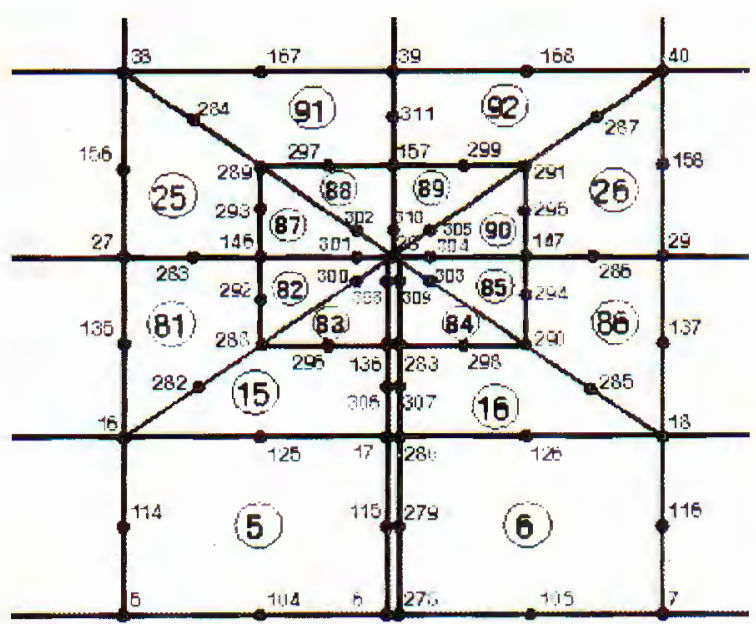

Fig. 4. Mesh around crack tip with Barsoum element $x / L=0.5$ an increment of 0.125 . The results are compared with ANSYS program to verify the reliability of problem.

\subsection{Results}

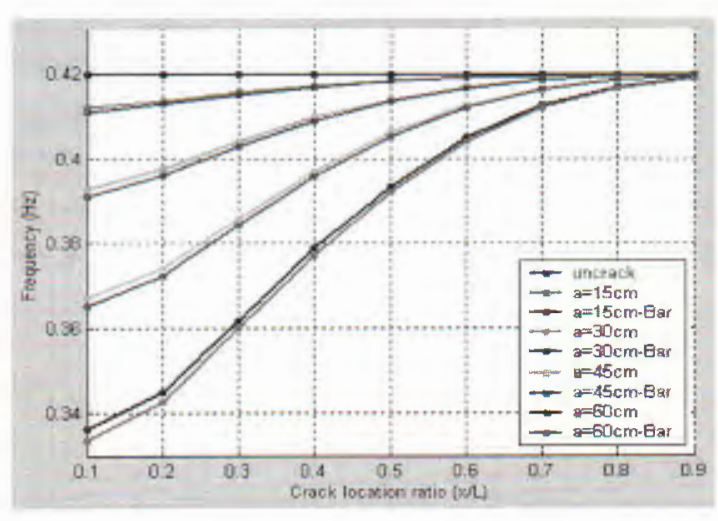

Fig. 5. Variation of the first natural frequency

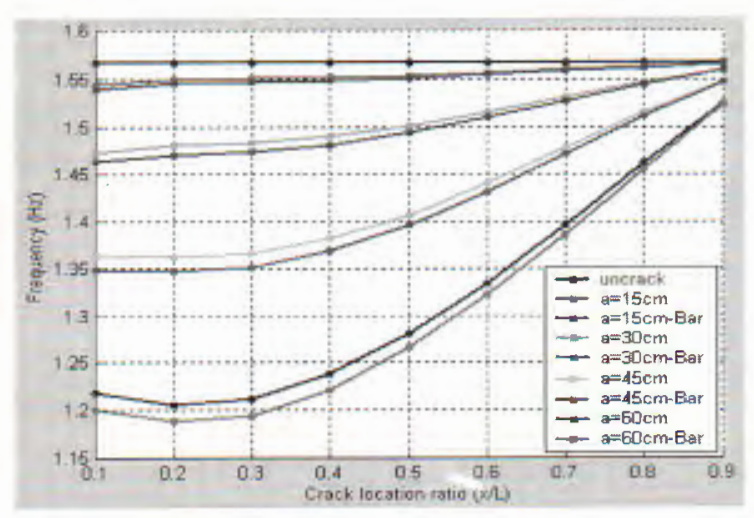

Fig. 6. Variation of the second natural frequency

The obtained numerical results from the CRACK-PLATE program are tabulated and plotted in the form of frequency versus the crack location ratio $(x / L)$ for various crack length ratio $(a / W)$. Figures 5-8 illustrate the variation of the first four natural frequencies in two cases: without and with element of Barsoum. For each crack length ratio $(a / W)$, the upper and lower lines correspond to the cases without and with Barsoum element, respectively. In the latter case, tables 1-4 show the variation of the first four natural frequencies as a function of the crack location and crack length for cantilever plate. The corresponding mode shapes are described by CRACK-PLATE program with crack location ratio of $x / L=0.5$ in Fig. 9 . 
Table 1. Variation of the first natural frequency depending on crack location and length

\begin{tabular}{|c|c|c|c|c|c|c|c|c|c|}
\hline \multirow{2}{*}{$\begin{array}{l}\text { Crack length } \\
\text { ratio }(a / W)\end{array}$} & \multicolumn{9}{|c|}{ Crack location ratio $(x / L)$} \\
\hline & 0.1 & 0.2 & 0.3 & 0.4 & 0.5 & 0.6 & 0.7 & 0.8 & 0.9 \\
\hline 0.000 & \multicolumn{9}{|c|}{0.4197} \\
\hline 0.125 & 0.4108 & 0.4128 & 0.4150 & 0.4168 & 0.4181 & 0.4189 & 0.4194 & 0.4196 & 0.4197 \\
\hline $\begin{array}{l}\text { Relative } \\
\text { diff. (\%) }\end{array}$ & -2.1206 & -1.6440 & -1.1198 & -0.6909 & -0.3812 & -0.1906 & -0.0715 & -0.0238 & 0 \\
\hline 0.250 & 0.3914 & 0.3962 & 0.4030 & 0.4089 & 0.4135 & 0.4165 & 0.4184 & 0.4193 & 0.4196 \\
\hline $\begin{array}{l}\text { Relative } \\
\text { diff. (\%) }\end{array}$ & -6.7429 & -5.5992 & -3.9790 & -2.5733 & -1.4772 & -0.7624 & -0.3097 & -0.0953 & -0.0238 \\
\hline 0.375 & 0.3652 & 0.3724 & 0.3845 & 0.3960 & 0.4053 & 0.4120 & 0.4162 & 0.4184 & 0.4194 \\
\hline $\begin{array}{l}\text { Relative } \\
\text { diff. (\%) }\end{array}$ & -12.9855 & -11.2699 & -8.3869 & -5.6469 & -3.4310 & -1.8346 & -0.8339 & -0.309 & -0.0715 \\
\hline 0.500 & 0.3336 & 0.3428 & 0.3599 & 0.3773 & 0.3925 & 0.4042 & 0.4120 & 0.4165 & 0.4188 \\
\hline $\begin{array}{l}\text { Relative } \\
\text { diff. }(\%)\end{array}$ & -20.5146 & -18.3226 & -14.2483 & -10.1024 & -6.4808 & -3.6931 & -1.8346 & -0.7624 & -0.2144 \\
\hline
\end{tabular}

Table.2. Variation of the second natural frequency depending on crack location and length

\begin{tabular}{|c|c|c|c|c|c|c|c|c|c|}
\hline \multirow{2}{*}{$\begin{array}{l}\text { Crack length } \\
\text { ratio }(a / W)\end{array}$} & \multicolumn{9}{|c|}{ Crack location ratio $(x / L)$} \\
\hline & 0.1 & 0.2 & 0.3 & 0.4 & 0.5 & 0.6 & 0.7 & 0.8 & 0.9 \\
\hline 0.000 & \multicolumn{9}{|c|}{1.5668} \\
\hline 0.125 & 1.5393 & 1.5455 & 1.5469 & 1.5485 & 1.5511 & 1.5544 & 1.5581 & 1.5617 & 1.5651 \\
\hline $\begin{array}{l}\text { Relative } \\
\text { diff. (\%) }\end{array}$ & -1.7552 & -1.3594 & -1.2701 & -1.1680 & -1.0020 & -0.7914 & -0.5553 & -0.3255 & -0.1085 \\
\hline 0.250 & 1.4639 & 1.4708 & 1.4739 & 1.4812 & 1.4938 & 1.5099 & 1.5274 & 1.5444 & 1.5588 \\
\hline $\begin{array}{l}\text { Relative } \\
\text { diff. (\%) }\end{array}$ & -6.5675 & -6.1271 & -5.9293 & -5.4634 & -4.6592 & -3.6316 & -2.5147 & -1.4296 & -0.5106 \\
\hline 0.375 & 1.3497 & 1.3480 & 1.3519 & 1.3685 & 1.3965 & 1.4322 & 1.4720 & 1.5118 & 1.5462 \\
\hline $\begin{array}{l}\text { Relative } \\
\text { diff. (\%) }\end{array}$ & -13.8563 & -13.9647 & -13.7158 & -12.6564 & -10.8693 & -8.5907 & -6.0505 & -3.5103 & -1.3148 \\
\hline 0.500 & 1.2007 & 1.1882 & 1.1947 & 1.2223 & 1.2666 & 1.3224 & 1.3861 & 1.4553 & 1.5224 \\
\hline $\begin{array}{l}\text { Relative } \\
\text { diff. \%) }\end{array}$ & -23.3661 & -24.1639 & -23.7490 & -21.9875 & -19.1601 & -15.5987 & -11.5331 & -7.1164 & -2.8338 \\
\hline
\end{tabular}

Table 3. Variation of the third natural frequency depending on crack location and length

\begin{tabular}{|c|c|c|c|c|c|c|c|c|c|}
\hline \multirow{2}{*}{$\begin{array}{l}\text { Crack length } \\
\text { ratio }(a / W)\end{array}$} & \multicolumn{9}{|c|}{ Crack location ratio $(x / L)$} \\
\hline & 0.1 & 0.2 & 0.3 & 0.4 & 0.5 & 0.6 & 0.7 & 0.8 & 0.9 \\
\hline 0.000 & \multicolumn{9}{|c|}{2.5940} \\
\hline 0.125 & 2.5686 & 2.5871 & 2.5814 & 2.5645 & 2.5533 & 2.5563 & 2.5701 & 2.5847 & 2.5923 \\
\hline $\begin{array}{l}\text { Relative } \\
\text { diff. \%) }\end{array}$ & -0.9792 & -0.2660 & -0.4857 & -1.1372 & -1.5690 & -1.4533 & -0.9213 & -0.3585 & -0.0655 \\
\hline 0.250 & 2.5078 & 2.5525 & 2.5372 & 2.4884 & 2.4550 & 2.4613 & 2.5018 & 2.5502 & 2.5820 \\
\hline $\begin{array}{l}\text { Relative } \\
\text { diff. \%) }\end{array}$ & -3.3230 & -1.5998 & -2.1896 & -4.0709 & -5.3585 & -5.1156 & -3.5543 & -1.6885 & -0.4626 \\
\hline 0.375 & 2.4174 & 2.4756 & 2.4533 & 2.3767 & 2.3189 & 2.3202 & 2.3786 & 2.4634 & 2.5430 \\
\hline $\begin{array}{l}\text { Relative } \\
\text { diff. \%) }\end{array}$ & -6.8080 & -4.5644 & -5.4240 & -8.3770 & -10.6052 & -10.5551 & -8.3038 & -5.0347 & -1.9661 \\
\hline 0.500 & 2.3012 & 2.3599 & 2.3366 & 2.2441 & 2.1629 & 2.1475 & 2.1972 & 2.2801 & 2.4081 \\
\hline $\begin{array}{l}\text { Relative } \\
\text { diff. \%) }\end{array}$ & -11.2876 & -9.0247 & -9.9229 & -13.4888 & -16.6191 & -17.2128 & -15.2968 & -12.1010 & -7.1665 \\
\hline
\end{tabular}


Table 4. Variation of the fourth natural frequency depending on crack location and length

\begin{tabular}{|c|c|c|c|c|c|c|c|c|c|}
\hline \multirow{2}{*}{$\begin{array}{l}\text { Crack length } \\
\text { ratio }(a / W)\end{array}$} & \multicolumn{9}{|c|}{ Crack location ratio $(x / L)$} \\
\hline & 0.1 & 0.2 & 0.3 & 0.4 & 0.5 & 0.6 & 0.7 & 0.8 & 0.9 \\
\hline 0.000 & \multicolumn{9}{|c|}{5.1174} \\
\hline 0.125 & 5.0418 & 5.0673 & 5.0710 & 5.0695 & 5.0630 & 5.0531 & 5.0481 & 5.0580 & 5.0891 \\
\hline $\begin{array}{l}\text { Relative } \\
\text { diff. \%) }\end{array}$ & -1.4773 & -0.9790 & -0.9067 & -0.9360 & -1.0630 & -1.2565 & -1.3542 & -1.1607 & -0.5530 \\
\hline 0.250 & 4.7863 & 4.8640 & 4.9412 & 4.9807 & 4.9311 & 4.8255 & 4.7509 & 4.7756 & 4.9343 \\
\hline $\begin{array}{l}\text { Relative } \\
\text { diff. \%) }\end{array}$ & -6.4701 & -4.9517 & -3.4431 & -2.6713 & -3.6405 & -5.7041 & -7.1618 & -6.6792 & -3.5780 \\
\hline 0.375 & 4.3587 & 4.5295 & 4.7610 & 4.9040 & 4.6988 & 4.3866 & 4.1998 & 4.1739 & 4.3984 \\
\hline $\begin{array}{r}\text { Relative } \\
\text { diff. \%) }\end{array}$ & -14.8259 & $-11,4882$ & -6.9645 & -4.1701 & -8.1799 & -14.2807 & -17.9310 & -18.4371 & -14.0501 \\
\hline 0.500 & 3.9211 & 4.2147 & 4.5876 & 4.8506 & 4.2310 & 3.8088 & 3.6123 & 3.5494 & 3.5337 \\
\hline $\begin{array}{l}\text { Relative } \\
\text { diff. \%) }\end{array}$ & -23.3771 & -17.6398 & -10.3529 & -5.2136 & -17.3213 & -25.5716 & -29.4114 & -30.6405 & -30.9473 \\
\hline
\end{tabular}

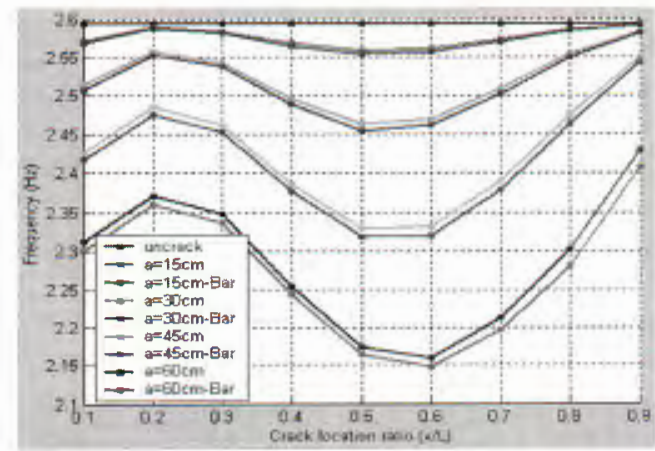

Fig. 7. Variation of the third natural frequency
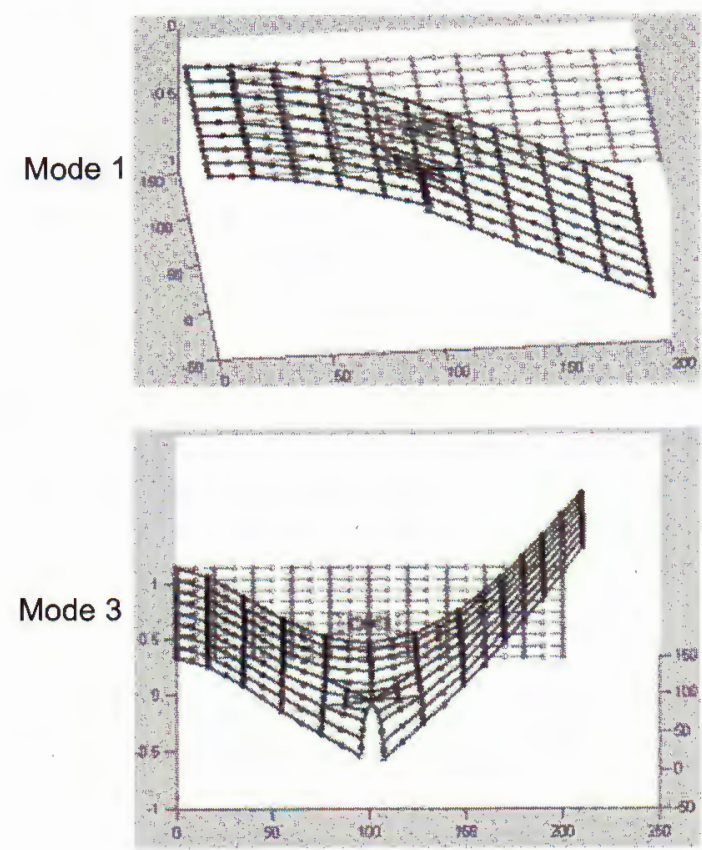

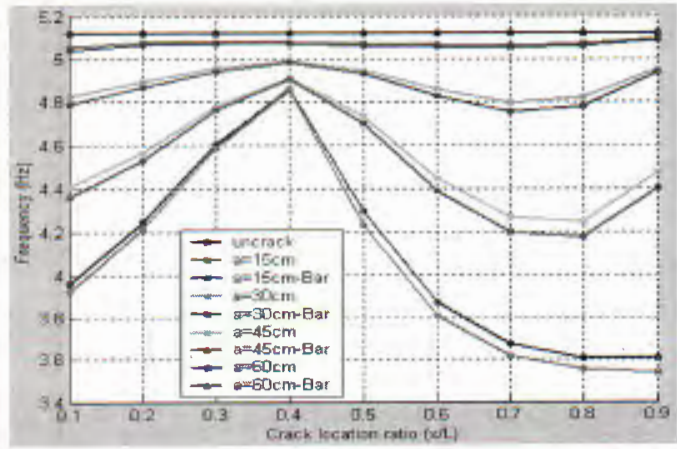

Fig. 8. Variation of the fourth natural frequency

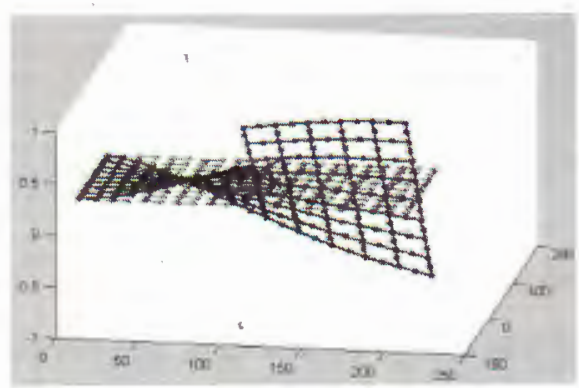

Mode 2

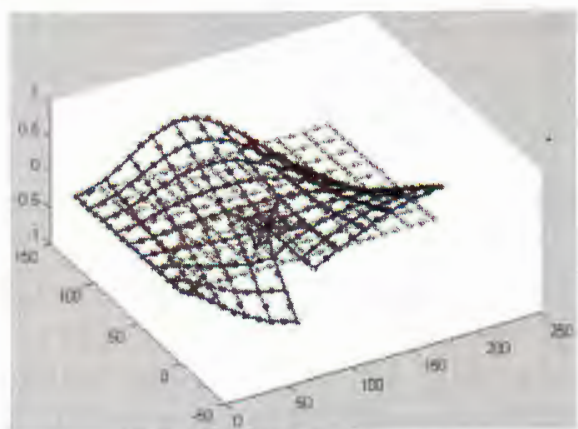

Mode 4

Fig. 9. Mode shapes description by Matlab $(x / L=0.5)$ 


\subsection{Results in comparing with ANSYS program}

To verify the reliability of the CRACK-PLATE program, the investigative results are compared with ANSYS program for the crack length $a=60 \mathrm{~cm}(a / W=0.5)$. In the ANSYS program, the SHELL 93 element is used.

Table 5. Comparison of the first natural frequency by CRACK-PLATE and ANSYS

\begin{tabular}{|c|c|c|c|c|c|c|c|c|c|}
\hline \multirow{2}{*}{ Mode 1 } & \multicolumn{8}{|c|}{ Crack location ratio $(x / L)$} \\
\cline { 2 - 10 } & 0.1 & 0.2 & 0.3 & 0.4 & 0.5 & 0.6 & 0.7 & 0.8 & 0.9 \\
\hline CRACK-PLATE & 0.3336 & 0.3428 & 0.3599 & 0.3773 & 0.3925 & 0.4042 & 0.4120 & 0.4165 & 0.4188 \\
\hline ANSYS & 0.3318 & 0.3410 & 0.3582 & 0.3761 & 0.3917 & 0.4038 & 0.4121 & 0.4169 & 0.4196 \\
\hline Error (\%) & $\mathbf{0 . 5 3 9 6}$ & 0.5251 & 0.4723 & 0.3180 & 0.2038 & 0.0989 & 0.0243 & 0.0959 & 0.1906 \\
\hline
\end{tabular}

Table 6. Comparison of the second natural frequency by CRACK-PLATE and ANSYS

\begin{tabular}{|c|c|c|c|c|c|c|c|c|c|}
\hline \multirow{2}{*}{ Mode 1 } & \multicolumn{8}{|c|}{ Crack location ratio $(x / L)$} \\
\cline { 2 - 10 } & 0.1 & 0.2 & 0.3 & 0.4 & 0.5 & 0.6 & 0.7 & 0.8 & 0.9 \\
\hline CRACK-PLATE & 1.2007 & 1.1882 & 1.1947 & 1.2223 & 1.2666 & 1.3224 & 1.3861 & 1.4553 & 1.5224 \\
\hline ANSYS & 1.1968 & 1.1841 & 1.1904 & 1.2183 & 1.2640 & 1.3204 & 1.3853 & 1.4568 & 1.5254 \\
\hline Error (\%) & 0.3248 & 0.3450 & $\mathbf{0 . 3 5 9 9}$ & 0.3272 & 0.2053 & 0.1512 & 0.0577 & 0.1029 & 0.1967 \\
\hline
\end{tabular}

Table \%. Comparison of the third natural frequency by CRACK-PLATE and ANSYS

\begin{tabular}{|c|c|c|c|c|c|c|c|c|c|}
\hline \multirow{2}{*}{ Mode 1 } & \multicolumn{10}{|c|}{ Crack location ratio $(x / L)$} \\
\cline { 2 - 10 } & 0.1 & 0.2 & 0.3 & 0.4 & 0.5 & 0.6 & 0.7 & 0.8 & 0.9 \\
\hline CRACK-PLATE & 2.3012 & 2.3599 & 2.3366 & 2.2441 & 2.1629 & 2.1475 & 2.1972 & 2.2801 & 2.4081 \\
\hline ANSYS & 2.2973 & 2.3559 & 2.3320 & 2.2373 & 2.1541 & 2.1375 & 2.1884 & 2.2755 & 2.4099 \\
\hline Error (\%) & 0.1695 & 0.1695 & 0.1969 & 0.3030 & $\mathbf{0 . 4 0 6 8}$ & $\mathbf{0 . 4 6 5 6}$ & 0.4005 & 0.2017 & 0.0747 \\
\hline
\end{tabular}

Table 8. Comparison of the fourth natural frequency by CRACK-PLATE and ANSYS

\begin{tabular}{|c|c|c|c|c|c|c|c|c|c|}
\hline \multirow{2}{*}{ Mode 1 } & \multicolumn{8}{|c|}{ Crack location ratio $(x / L)$} \\
\cline { 2 - 10 } & 0.1 & 0.2 & 0.3 & 0.4 & 0.5 & 0.6 & 0.7 & 0.8 & 0.9 \\
\hline CRACK-PLATE & 3.921 .1 & 4.2147 & 4.5876 & 4.8506 & 4.2310 & 3.8088 & 3.6123 & 3.5494 & 3.5337 \\
\hline ANSYS & 3.9255 & 4.2131 & 4.5865 & 4.8512 & 4.2360 & 3.8076 & 3.6057 & 3.5438 & 3.5359 \\
\hline Error (\%) & 0.1121 & 0.0379 & 0.0239 & 0.0124 & 0.1180 & 0.0315 & 0.1827 & 0.1578 & 0.0622 \\
\hline
\end{tabular}

\subsection{Discussion}

From the above results and figures, the following observations are made:

- The first four natural frequencies are decreased depending on the crack location and crack length. The longer crack length causes the higher change in frequency.

- The first natural frequency is mostly affected as the crack is located near to the fixed end of plate $(x / L=0.1)$. When the crack moves towards the free end of plate, the first natural frequency is less affected. As indicated in the Table 1 and Fig. 5, the crack occurring near to the free end of plate $(x / L=0.9)$ does not almost change the first frequency.

- For the second natural frequency, the maximum changes of frequency takes place as the crack occurs near to the fixed end of plate $(x / L=0.1 ; 0.2)$. When the crack moves towards the free end of plate, the second natural frequency is less affected and almost unaffected for a crack located at $x / L=0.9$. The most reduction is $24.16 \%$ with $a / W=$ 0.5 (Table 2, Fig. 6). 
- For the plate with a crack is located at the center of the plate $(x / L=0.5 ; 0.6)$, the third natural frequency is the highest decreased. When the crack is located near to the fixed end of plate $(x / L=0.1)$, the third natural frequency is more affected than at the other end of plate (Table 3, Fig. 7).

- As indicated in the Table 4 and Fig. 8 , the reduction of the fourth natural frequency depends on the crack length. The most reduction is $30.95 \%$ when the crack is located at the free end of plate $(x / L=0.9)$ with $a / W=0.5$.

From the above observations, it can be stated that the first four natural frequencies are very sensitive to the crack location and crack length for cracked plate. Among them, the second and fourth natural frequencies are most sensitive. This can be explained by the fact that the second and fourth modes are greatly influenced by the tearing mode (mode III) of crack opening deformation. Therefore, we can base on the sensitiveness of the first four natural frequencies to detect crack in bending thin cantilever plate.

The investigative results are reliable when compared with ANSYS program. The highest error between CRACK-PLATE and ANSYS program is 0.54\% (table 5-8). Comparing CRACK-PLATE and ANSYS programs, we notice that the CRACK-PLATE program is more efficient. This program allows us to investigate the influence of crack location along the whole length of the plate with an iterative procedure, while the ANSYS program only treats the problem at each crack location with more times and efforts.

The procedure using degenerated element of Barsoum gives lower frequencies than the case without the Barsoum element (Figures 5-8), with the relative difference up to $1.92 \%$ for the fourth frequency when $a / W=0.5, x / L=0.9$.

\section{CONCLUSION}

Investigation of the influence of crack on the first four natural frequencies of vibrating bending thin plate has been presented in this paper. The dynamical behavior of the cracked plate is shown to be very sensitive to the crack location and crack length. It can be concluded that the CRACK-PLATE program by the finite element method, based on the Ressner-Mindlin' theory of plate with the singularity element of Barsoum, is efficient and reliable for the analysis of cracked bending thin plate problem. For further development, this forward study can be used to carry out the inverse problem for crack detection in bending thin plate using changes in frequencies.

Acknowledgement. This work is completed with the support of Natuial Science Council of Vietnam.

\section{REFERENCES}

1. G. M. Owolabi, A. S. J. Swamidas, R. Seshadri, Crack detection in beams using changes in frequencies and amplitudes of frequency response functions, Journal of Sound and Vibration 265 (2003) 1-22.

2. N. T. Khiem, T. V. Lien, A simplified method for natural frequency analysis of multiple cracked beam, Journal of Sound and Vibration 254 (2001) 737-751.

3. P. Cawley, R. D. Adams, The location of defects in structures from measurements of natural frequencies, Journal of Strain Analysis 14 (1979) 49-57. 
4. 'D. Wu, S. S. Law, Damage localization in plate structures from uniform load surface curvature, Journal of Sound and Vibration 276 (2004) 227-244.

5. W. Clough and J. Penzien, Dynamics of Structures, $2^{\text {nd }}$ edition, McGraw- Hill, 1993.

6. T. L. Anderson, Fracture Mechanics: Fundamentals and Applications, second edition, CRC Press LLC, 1995.

7. Y. W. Kwon, H. Bang, The Finite Element Method Using Matlab, CRC Press, 1997.

8. R. S. Barsoum, Triangular quarter - point elements as elastic and perfectly - plastic crack tip elements, International Journal for Numerical Methods in Engineering 11 (1977) 85-98.

9. Vuong Quang Giang, Studying effect of cracks on the dynamic characteristics of bending thin plate, Master Thesis, Ho Chi Minh City University of Technology, 2004.

Received March 1, 2005

Revised July 11, 2005

\section{ẢNH HƯớNG CƯA VẾT NỨT BIÊN ĐẾN TẦN SỐ CƯA TẨM MÒNG CHIIU UỐN}

Bài báo nghiên cứu ành hường của vị trí và chiều dài vết nứt đến tần số dao động riêng của tấm mơng chịu uốn. Một chương trình máy tính sử dụng phương pháp phần tứ hữu hạn gọi là CRACK-PLATE, đã được thiết lập trên cơ sở lý thuyết tấm Ressner-Minlin để thực hiện việc phân tích trên. Để thu được kết quả với độ chính xác cao, phần tứ Barsoum được kết hợp sứ dụng với phần từ tấm 8 nút. Kết quả phân tích số cho thấy tần số dao động riêng của tấm rất nhạy cảm với vết nứt. Kết quả nghiên cứu này là cơ sở để giải quyết bài toán chẳn đoán vết nứt của tấm bằng các tần số riêng. 